$14,09,15$

\title{
Особенности локальной динамики и ориентационного состояния жесткоцепных жидкокристаллических полимеров
}

\author{
(C) В.А. Рыжов, В.В. Жиженков, Н.Г. Квачадзе \\ Физико-технический институт им. А.Ф. Иофрфе РАН, \\ Санкт-Петербург, Россия \\ E-mail: v.ryzhov@mail.ioffe.ru
}

(Поступила в Редакцию 18 августа 2018 г.)

Получены и проанализированы спектры протонного магнитного резонанса (ПМР) и терагерцовые ИК-спектры волокон и гранул Vectra A950, а также волокон типа Армос до и после термообработки с целью понять молекулярные механизмы подвижности, обеспечивающие самоорганизацию и перестройку структуры этих жесткоцепных жидкокристаллических полимеров, их сходство и различие. Показано, что крупномасштабная тепловая (квазисегментальная) подвижность в таких ЖК-полимерах осуществляется за счет рептации макромолекул относительно друг друга, а необходимые для перемещения цепей конформационные переходы в них есть результат случайного накопления смещений, возникающих при локальных изгибных и крутильно-колебательных движениях в звеньях полимерных цепей по механизму типа Бреслера-Френкеля.

DOI: $10.21883 /$ FTT.2019.02.47141.218

\section{1. Введение}

В настоящее время созданию и изучению высокопрочных, термо- и огне-стойких синтетических волокон для современной высокотехнологичной индустрии уделяется самое пристальное внимание. Отечественная и зарубежная практика их использования показала, что самыми рекордными характеристиками обладают волокна из лиотропных систем на основе гетероциклических полиимидов и ароматических параарамидов, а также термотропные системы на основе жидкокристаллических (ЖК) сополиэфиров типа Vectra и т.п.

Несмотря на различие методов получения этих жесткоцепных ЖК-полимеров, высокая молекулярная ориентация, необходимая для реализации больших значений прочности и модуля упругости, в обоих случаях достигается в процессе формирования волокон при фильерной вытяжке [1]. Для дальнейшего (причем существенного) повышения прочности эти волокна подвергаются так называемой термообработке (ТО) - прогреву в определенных температурно-временных режимах. При ТО за счет спонтанной самоорганизации улучшается надмолекулярная структура полимера, а также может происходить удаление из волокон продуктов деструкции, дополиконденсация, кристаллизация и образование сшивок [2].

Для таких масштабных перестроек высоко ориентированные макромолекулы должны иметь подвижность, по крайней мере, подобную сегментальной подвижности в гибкоцепных полимерах. Выяснение молекулярных механизмов подвижности в таких системах и является предметом настоящей работы.

Ранее в серии работ по изучению молекулярной подвижности в ЖК-полимерах методом ЯМР широких линий [3-6] было установлено, что масштабные перестройки в процессах самоорганизации и упрочнения ЖК-полимерных волокон обеспечиваются специ- фическим кооперативным движением макромолекул в ЖК-состоянии, названным авторами „квазисегментальным“. Данная работа экспериментальная, использующая ИК-спектроскопию среднего и терагерцового диапазонов с целью получить дополнительные сведения о „квазисегментальной“ подвижности в подобных жесткоцепных полимерах.

Привлечение ИК-спектроскопии терагерцового (FIR) диапазона представляет особый интерес для физикохимии ЖК-полимеров. Непосредственно участвующие в молекулярной динамике ИК-активные степени свободы в этом диапазоне соответствуют высокочастотным релаксационным и большеамплитудным крутильным колебаниям фрагментов цепей, а также их коррелированному движению, обеспечивающему конформационную перестройку [7]. Кроме того, один из главных механизмов, лежащих в основе формирования FIR-спектров поглощения, носит ярко выраженный межмолекулярный характер. Вместе с тем, сам факт существования жидкокристаллического состояния во многом обусловлен именно наличием сил межмолекулярного взаимодействия [8].

\section{2. Методика}

Объектами исследования служили: 1) ЖК-сополимер промышленной марки Vectra A 950, имеющий формулу

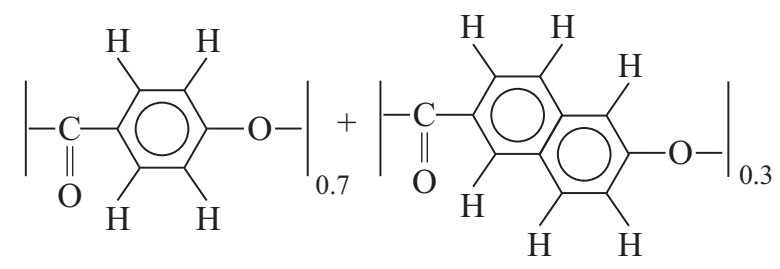

и содержащий 70 mol.\% фрагментов 4-гидрокси-бензойной кислоты и 30 mol.\% 6-гидрокси-2-нафтойной кисло- 
ты и 2) ЖЦ-сополимер типа Armos, имеющий формулу<smiles>CNc1ccc(C(=O)Nc2ccc(C(C)(C)C)cc2)cc1</smiles><smiles>CNc1ccc2c(c1)NC(c1ccc(NC(=O)c3ccc(C(C)(C)C)cc3)cc1)N2</smiles>

и образованный реакцией поликонденсации п-фенилен диамина и 5-амино-2-(п-аминофенил) бензимидазола с терефталевой кислотой.

ЖК-сополимер Vectra А950 имеет в основной цепи две мезогенных группы, которые не разделены гибкими развязками. Это придает макромолекулам сополимера жесткость, сильно снижая молекулярную подвижность его цепей [9]. Мезогены макромолекул сополимера Armos также не разделены гибкими развязками. Дополнительную молекулярную жесткость, обеспечивающую высокую термическую стабильность и выдающиеся механические свойства этого сополимера придают сопряженные бензимидозольные и фенольные кольца в основной цепи, а также Н-связи между цепями.

Исследование сополимера Vectra А950 проводилось на образцах в виде гранул и волокон. Гранулы сополимера были получены формованием исходного материала фирмы Hoechst-Celanese corp. Его волокна изготовлены на лабораторной установке ФТИ по методике [10]. Образцы сополимера Armos производства ОАО Химволокно (Тверь) были получены в виде волокон: исходных и прошедших TO.

Измерение ИК-спектров пропускания исследованных образцов Vectra A950 и Armos проводилось на двух приборах: в средней ИК-области $4000-400 \mathrm{~cm}^{-1}$ на спектрофотометре Perkin-Elmer 577 с разрешением $2-4 \mathrm{~cm}^{-1}$, в дальней от 400 до $20 \mathrm{~cm}^{-1}$ на спектрометре Hitachi FIS 21 с разрешением $1-2 \mathrm{~cm}^{-1}$. Спектры гранул получали на образцах, изготовленных в виде таблеток из смеси $1: 100$ гранул с ПЭ. Для получения спектров волокон нити образца регулярно укладывались на рамке размером $20 \times 12 \mathrm{~mm}$. Поляризаторами при работе в средней ИК-области служили решетки на подложке из фторопласта $\left(4000-1150 \mathrm{~cm}^{-1}\right)$ и полиэтилена $\left(1150-400 \mathrm{~cm}^{-1}\right)$, a в далекой ИК (FIR-области) поляризация излучения осуществлялась с помощью полиэтиленовой реплики дифракционной решетки с 1200 штрихов на миллиметр.

Другим методом исследования был протонный магнитный резонанс (ПМР). Он позволял следить как за крупномасштабным движением макромолекул при высоких температурах, так и за изменением структуры ЖК-полимеров. Спектры ПМР регистрировали в температурном диапазоне от -160 до $330^{\circ} \mathrm{C}$ на спектрометре
ЯМР широких линий, разработанном и изготовленном в ФТИ им. А.Ф. Иоффе [11].

\section{3. Результаты и их обсуждение}

ИК-спектры гранул и нитей Vectra A950 в области $4000-400 \mathrm{~cm}^{-1}$ представлены на рис. 1. Отнесение полос в этих спектрах сделано в работах $[9,12]$. Спектры среднего ИК-диапазона (в том числе и поляризационные) этих образцов оказались практически одинаковыми, видимо потому, что короткодействующие внутримолекулярные силы в нитях существенно не отличаются от таковых в гранулах. Зарегистрированные длинноволновые ИК-спектры гранул и нитей Vectra A950 в области $400-20 \mathrm{~cm}^{-1}$ представлены на рис. 2.

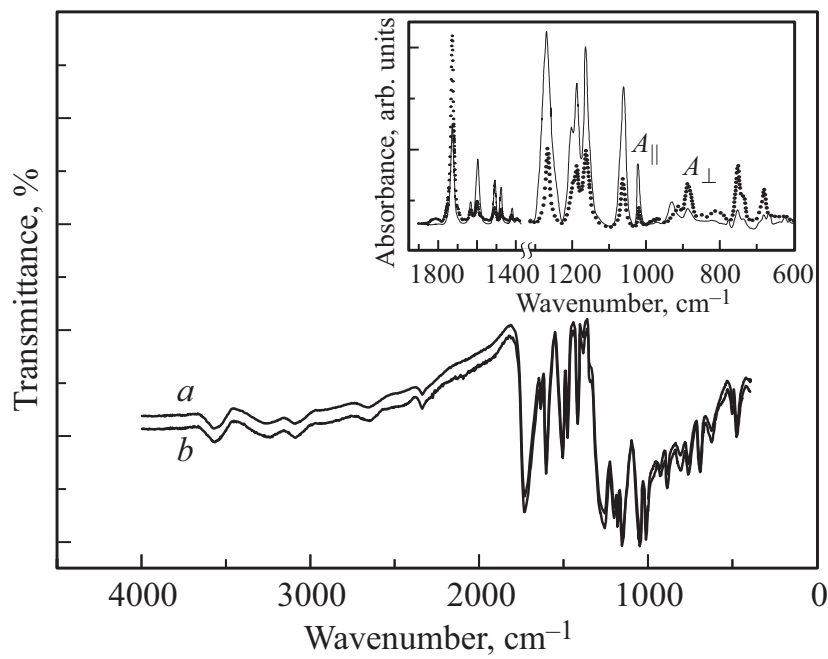

Рис. 1. ИК-спектр Vectra A950. Гранулы $-a$, нити $-b$. Для наглядности спектр нитей смещен по ординате. Врезка: поляризационные спектры поглощения Vectra A 950.

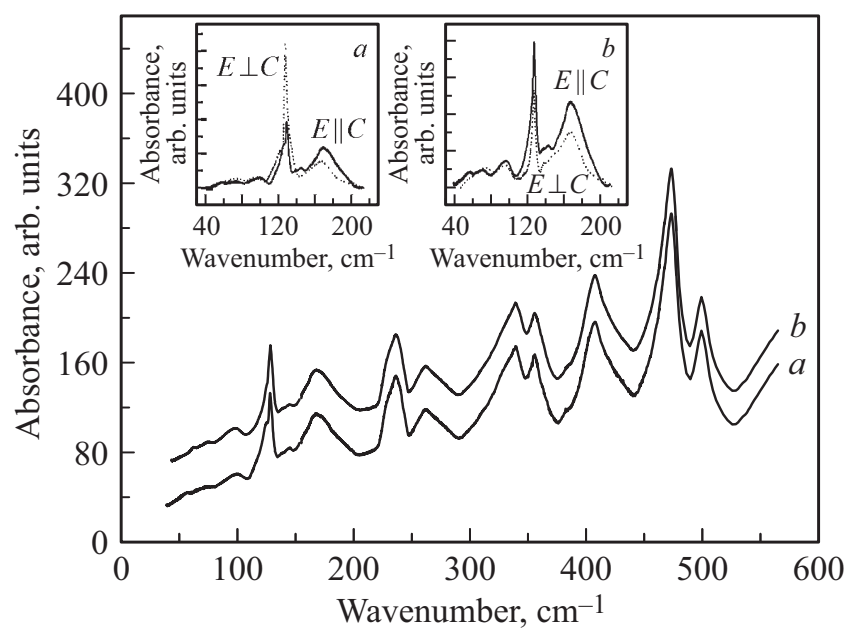

Рис. 2. FIR-спектры Vectra A950. Спектр нитей смещен по ординате. Врезка: поляризационные спектры поглощения Vectra A 950 гранулы $(a)$, нити $(b)$ в интервале $40-220 \mathrm{~cm}^{-1}$. 
Таблица 1. Спектральные характеристики ДИК-спектров поглощения ЖК-полимера Vectra A950

\begin{tabular}{|c|c|c|c|}
\hline \multirow{2}{*}{$\begin{array}{c}\text { Частоты полос } \\
\text { поглощения } \\
\text { Vectra A950 }\left(\mathrm{cm}^{-1}\right)\end{array}$} & \multirow[t]{2}{*}{ Интерпретация } & \multicolumn{2}{|c|}{$\begin{array}{c}\text { Дихроичное } \\
\text { отношение }\end{array}$} \\
\hline & & $R_{g}$ & $R_{f}$ \\
\hline 69 & $N$ ring либрация & 0.75 & 0.95 \\
\hline 96 & $B$ ring либрация & 0.95 & 1.15 \\
\hline 125 & поглощение Поли + $\tau$ СОО & 0.45 & 1.55 \\
\hline 143 & $v_{10 \mathrm{~b}} B$ ring & 1.65 & 1.55 \\
\hline 169 & 'Batterfly' $N$ ring & 1.50 & 1.55 \\
\hline 235 & $\delta \mathrm{CCC}$ & 1.42 & 1.33 \\
\hline 262 & $\tau \mathrm{COC}$ & 1.55 & 1.43 \\
\hline 338 & $v_{10 \mathrm{~b}} N$ ring & 1.55 & 1.43 \\
\hline 355 & 'Envelope flap' $N$ ring & 1.65 & 1.55 \\
\hline 407 & $v_{16 \mathrm{a}} B$ ring & 1.20 & 1.25 \\
\hline 475 & $v_{16 \mathrm{a}} N$ ring & 1.25 & 1.33 \\
\hline
\end{tabular}

Примечание. Символы: g - гранулы; $\mathrm{f}$ - волокна; $N$ ring нафталеновое кольцо; $B$ ring - бензольное кольцо; $v_{10 \mathrm{~b}}-, v_{16 \mathrm{a}}-$ валентные, $\tau$ - крутильные и $\delta$ - деформационные колебания.

Литературных данных по идентификации полос в FIRспектре Vectra A950, по-видимому, нет. Имеются лишь данные касающиеся низкочастотного поглощения в низкомолекулярных ЖК, но и они достаточно разрознены и относятся в основном к низкомолекулярным нематикам типа МББА (4-метокси-бензилиден-4-бутиланилин) с бензольными кольцами в качестве мезогенов и алкильными группами в качестве развязок [13]. Сведения же о поляризационных FIR-спектрах поглощения каких-либо ЖК-полимеров практически отсутствуют.

Для идентификации полос поглощения в FIR-спектре Vectra A 950 были использованы экспериментальные и расчетные литературные данные по длинноволновым спектрам гидрокси-бензойной кислоты [14] и гидроксинафтойной кислоты [15], входящими в состав этого сополимера. Проведенное на основании этих величин предварительное отнесение полос, а также их дихроичное отношение, полученное из наших поляризационных измерений на нитях и гранулах Vectra A950, представлено в табл. 1.

Для оценки параметра ориентационного порядка сополимера $S=\left(3\left\langle\cos ^{2} \Theta\right\rangle-1\right) / 2$, где $\Theta-$ угол между осью молекулы и осью волокна, использовалась формула $S=(R-1)\left(R_{0}+2\right) /(R+2)\left(R_{0}-1\right)$, где $R$ - дихроичное отношение, $R_{0}=2 \operatorname{Cot}^{2} \psi$, а $\psi-$ угол между моментом перехода и молекулярной осью цепи, параллельной в этом случае направлению вытяжки. Угол $\psi$ для основных составляющих Vectra A950 - бензольных колец и связей $\mathrm{C}-\mathrm{O}-\mathrm{C}-$ точно не известен, но в первом приближении может быть взят равным $0^{0}$, и тогда $S=(R-1) /(R+2)$. Дихроичное отношение определяли как отношение величины поглощения радиации, поляризованной параллельно молекулярной оси ЖК-полимера (и направлению вытяжки) $A_{\|}$, к величине поглощения радиации, поляризованной перпендикуляр- но направлению вытяжки $A_{\perp}$, т.е. $R=A_{\|} / A_{\perp}$. В свою очередь $A_{\|}=\ln \left(1 / T_{\|}\right)$, и $A_{\perp}=\ln \left(1 / T_{\perp}\right)$, где $T_{\|}$и $T_{\perp}$ пропускание поляризованной ИК-радиации с электрическим вектором $(E)$ параллельным и перпендикулярным направлению вытяжки $(C)$ (и щели прибора).

Из сравнения дихроичных отношений полос поглощения в FIR-спектрах гранул $\left(R_{g}\right)$ и в спектрах волокон $\left(R_{f}\right)$ видно, что величины $R_{g}$ и $R_{f}$ не сильно отличаются друг от друга, за исключением трех самых низкочастотных полос, характеризующих крутильные колебания (либрации) мезогенов (бензольных и нафталиновых колец сополимера). Особенно разнятся величины $R_{g}$ и $R_{f}$ (и, соответственно, параметры ориентационного порядка), полученные для полосы поглощения при $127 \mathrm{~cm}^{-1}$, которая здесь рассматривается, как поглощение по механизму Поли. Напомним, что термин „поглощении Поли“ используется в рамках наиболее распространенной и применяемой в настоящее время для интерпретации низкочастотных ИК-спектров конденсированных сред концепции [7], в основу которой положено представление о либрирующих молекулах (здесь мезогенах), находящихся в поле межмолекулярных сил. В данном случае, кроме того, учтено то, что в формировании низкочастотного спектра могут принимать участие полярные фрагменты ЖК-полимера, способные совершать торсионные движения, а также другие возможные внутримолекулярные переориентации. Речь идет о вкладе в интенсивность и контур полосы поглощения при $127 \mathrm{~cm}^{-1}$ колебаний группы $\mathrm{COO}$, связывающей мезогены и способствующей конформационной подвижности полимерных цепей. Такие внутримолекулярные колебания, как ожидается, имеют место в области $100-150 \mathrm{~cm}^{-1}$, тогда как „поглощение Поли“ в спектрах жидкостей и полимеров обычно проявляется на частотах $10-100 \mathrm{~cm}^{-1}$, да и качественная оценка частоты поглощения Поли для Vectra A950 по обычной схеме [9] дает значение $v_{\mathrm{lib}}=65 \mathrm{~cm}^{-1}$. Это обстоятельство, поскольку интенсивность полосы при $127 \mathrm{~cm}^{-1}$ довольно значительна, приводит авторов, изучавших FIR-спектры мезоморфных веществ $[9,16]$, к заключению о специфике либрационного движения в ЖК. Они полагают, что разница между вычисленным значением частоты либрации и частотой эксперимента является следствием более глубокой и более узкой энергетической ямы, в которой либрируют мезогены. ЖК-среда обеспечивает более крутую потенциальную яму по отношению к угловым смещениям вокруг длинной оси мезогена (то есть с меньшим моментом инерции и менее затрудненным вращением) и, следовательно, более высокое значение либрационной частоты.

Такое подробное обсуждение отнесения поглощения при $127 \mathrm{~cm}^{-1}$ в FIR-спектре Vectra A950 понадобилось потому, что именно эта полоса оказалась наиболее чувствительной к ориентационному упорядочению сополимера. Дихроичные отношения большинства полос FIR-спектра (см. табл. 1) и полос в средней ИК-области (см. рис. 1) для гранул и волокон примерно одинаковы 


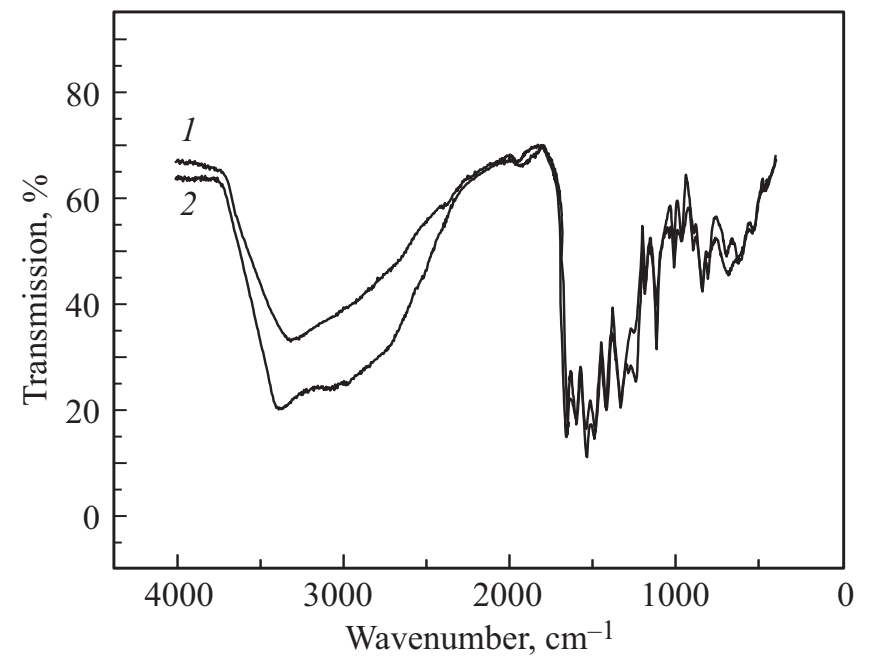

Рис. 3. ИК-спектры Армос. Волокна исходные - 1, термообработанные -2 .

$R_{g} \approx R_{f}$, а если и отличаются, то незначительно, в пределах погрешности измерений. Например, дихроичное отношение полосы валентного колебания карбонильной группы при $1727 \mathrm{~cm}^{-1}$ спектра гранул $R_{g}=0.85$, а в спектре волокон $R_{f}=1.3$, тогда как аналогичные величины для полосы при $127 \mathrm{~cm}^{-1}$ в FIR-спектре отличаются в несколько раз: $R_{g}=0.45$ и $R_{f}=1.55$.

В итоге, параметры ориентационного порядка, полученные по полосе валентных колебаний для гранул и волокон (средний ИК-диапазон), практически совпадают, что не позволяет уверенно говорить о различной ориентации фрагментов цепей в гранулах и волокнах. Тогда как параметры ориентационного порядка, полученные по полосе торсионных колебаний при $127 \mathrm{~cm}^{-1}$ для гранул и волокон различны. Их значения равны $S_{g}=-0.22, S_{f}=0.15$, что позволяет с большей определенностью различать ориентацию цепей в волокнах и в гранулах.

В отличие от ЖК-сополимера Vectra A950, у полимера Армос макромолекулы обладают большей жесткостью и, соответственно, менее подвижны. На рис. 3 показаны ИК-спектры его волокон в области $4000-400 \mathrm{~cm}^{-1}$ до и после термообработки. Отнесение полос в ИК-спектрах Армос представлено в работах $[17,18]$.

Термообработка, как видно из рис. 3, приводит к существенному изменению ИК-спектра. Особенно на частотах проявления валентных колебаний в NH-группах $\left(3700-2500 \mathrm{~cm}^{-1}\right)$, связанных водородной связью (ВС). Перераспределение в интенсивности и смещение полос поглощения наблюдается также и на частотах проявления валентных колебаний в $\mathrm{C}=\mathrm{O}$ группах и на частотах деформационных колебаний в NH группах в области $1700-500 \mathrm{~cm}^{-1}$. Подобные изменения свидетельствуют не только о преобразовании системы водородных связей в макромолекулах полимера при термообработке, но и о структурной перестройке самих полимерных цепей.
Так, рост интенсивности низкочастотного крыла аномально широкой полосы в интервале $3300-2800 \mathrm{~cm}^{-1}$ связывают $[19,20]$ с усилением внутримолекулярной ВС в бензимидазольных и амидных фрагментах.

О том, что сильные ВС между бензимидазольными фрагментами играют важную роль в формировании межмолекулярных ассоциатов в полимерных цепях Армос, свидетельствуют также изменения в области $1700-500 \mathrm{~cm}^{-1}$. Здесь наблюдается перераспределение интенсивности в полосе при $1664 \mathrm{~cm}^{-1}$ (так называемый амид 1) в пользу ее высокочастотной составляющей, а тоже в дублете при $1324-1250 \mathrm{~cm}^{-1}$ (так называемый амид 3). Полоса при $\sim 690 \mathrm{~cm}^{-1}$ (деформационное колебание $\mathrm{NH}$ ) проявляет свою структуру, подразумевающую появление упорядоченных областей в полимере после ТО.

Дополнительную информацию относительно изменений, вызванных TO Армос, несут FIR-спектры в области $20-500 \mathrm{~cm}^{-1}$, в которой проявляются торсионные (крутильные) колебания на связях $\mathrm{C}-\mathrm{O}, \mathrm{C}-\mathrm{C}, \mathrm{C}-\mathrm{N}$ и $\mathrm{N}-\mathrm{H}$, а также либрационные колебания бензольных и фенил бензимидазольных колец, то есть динамика более масштабных, чем межатомные колебания, группировок. На рис. 4 представлены эти спектры для исходных и термообработанных волокон Армос. Видно, что FIRспектр волокон Армос, подвергнутых термообработке, значительно отличается от спектра исходных волокон особенно на самых низких частотах.

Для идентификации полос поглощения в FIRспектре Армос были использованы экспериментальные и расчетные литературные данные по терагерцовым ИК-спектрам аминофенил-бензимидозола $[21,22]$ и фенилен-терефталамида (РРТА) [23], входящими в состав мономерного звена этого полимере. Проведенное на основании этих данных предварительное отнесение полос в FIR-спектре волокон Армос представлено в табл. 2.

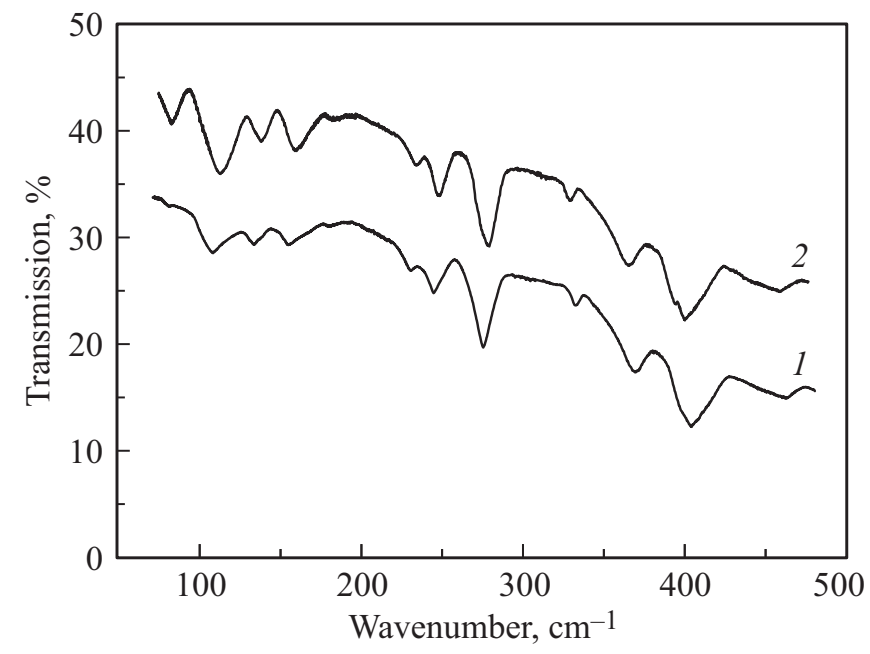

Pис. 4. FIR-спектры Армос. Волокна исходные - 1, термообработанные - 2. Спектры 2 смещены по ординате для наглядности. 
Таблица 2. Спектральные характеристики ДИК-спектров поглощения ЖЦ-полимера Армос

\begin{tabular}{|c|c|c|}
\hline $\begin{array}{c}\text { Частоты полос } \\
\text { поглощения } \\
\text { Armos }\left(\mathrm{cm}^{-1}\right)\end{array}$ & Интерпретация & $\begin{array}{c}\text { Молекулярная } \\
\text { динамика }\end{array}$ \\
\hline $\begin{array}{r}80 \\
111 \\
134 \\
157\end{array}$ & $\begin{array}{c}\tau \mathrm{CO}(69)+\tau(\mathrm{CC})(10)+\text { tr. } \\
\tau \mathrm{CCO}(28)+\tau B \operatorname{ring}(12)+\text { libr. } \\
\delta \mathrm{COC}(46)+\delta \mathrm{CC} B \operatorname{ring}(10)+\text { libr. } \\
\delta \mathrm{CCO}(20)+\tau B I Z \operatorname{ring}(34)+\text { libr. }\end{array}$ & $\begin{array}{c}\text { Решеточные } \\
\text { колебания }\end{array}$ \\
\hline $\begin{array}{l}228 \\
244 \\
275\end{array}$ & $\begin{array}{c}\tau B \operatorname{ring}(57)+\tau \mathrm{CC}(15) \\
\tau \mathrm{NH}(38)+\delta \mathrm{CC}(32)+\delta B \operatorname{ring}(28) \\
\tau B I Z \operatorname{ring}(45)+\tau \mathrm{CONH}(28)\end{array}$ & $\begin{array}{c}\text { Крутильные } \\
\text { колебания }\end{array}$ \\
\hline $\begin{array}{l}329 \\
364 \\
401 \\
475\end{array}$ & $\begin{array}{c}\delta \mathrm{CN}(39)+\gamma \mathrm{CO}(13) \\
\delta B I Z \operatorname{ring}(24)+\delta B \operatorname{ring}(14)+\gamma \mathrm{CC}(14) \\
\delta B \operatorname{ring}(74)+\gamma B \operatorname{ring}(14) \\
\gamma \operatorname{COC}(36)+\delta \operatorname{COC}(43)\end{array}$ & $\begin{array}{c}\text { Деформационные } \\
\text { колебания }\end{array}$ \\
\hline
\end{tabular}

Пр и м е ча н и е. Символы: tr. — трансляция; libr. — либрация; $\tau$--крутильные, $\delta$ и $\gamma$ - деформационные колебания, $B$ ring - бензольное кольцо, $B I Z$ ring — бензимидазольное кольцо.

Поглощение от собственных колебаний ВС лежит в этом же диапазоне и проявляется в FIR-спектре Армос фоном, полушириной и смещением максимума полос, поскольку колебания ВС в упорядоченных структурах не локализованы на отдельных группах, а являются вращательными или трансляционными колебаниями.

Выполненное отнесение означает, что весь FIR-спектр Армос в диапазоне $50-450 \mathrm{~cm}^{-1}$ фактически характеризует особенности ограниченного малоуглового движения фрагментов макромолекул этого полимера.

Как и в случае ЖК-сополимера Вектра А950, наиболее заметно изменился FIR-спектр волокон Армос после их термообработки на частотах проявления либрации мезогенных группировок. Правда, в отличие от ЖК Vectra, полоса поглощения по механизму Поли в спектре Армос четче проявила свою тонкую структуру решеточных колебаний, свидетельствуя о большей кристаллоподобной упорядоченности строения термообработанного полимера.

Другой спектральный эффект - высокочастотное смещение полос крутильных колебаний в интервале $200-300 \mathrm{~cm}^{-1}$. Полосы крутильных колебаний между бензольными кольцами и амидными группировками при 228 и $244 \mathrm{~cm}^{-1}$ смещены на $3-4 \mathrm{~cm}^{-1}$, а полоса крутильных колебаний между фениламидными сегментами и бензимидазольными кольцами при $275 \mathrm{~cm}^{-1}$ смещена на $\sim 4 \mathrm{~cm}^{-1}$. Эти изменения в спектре также свидетельствуют об ужесточении полимерных цепей Армос при термообработке.

Все эти изменения в малоугловой молекулярной динамике, несомненно, способствовали перераспределению ВC в макромолекулах Армос при ТО, фиксируемую по спектрам среднего ИК-диапазона (см. рис. 3). Однако для структурной модификации Армос при температурном отжиге не обойтись без крупномасштабного движения цепей. Такое, названное авторами „квазисегменталь- ным“, тепловое движение цепей подробно исследовано в серии работ [3-6,24,25] методом протонного магнитного резонанса (ПМР) широких линий.

Ниже приводятся отдельные результаты этих исследований молекулярного движения и структурных изменений в поли-пара-арамидных волокнах Армос при термообработке. Сравнение спектров ПМР (рис. 5) свежесформованных и термообработанных волокон Армос при низких температурах в условиях жесткой решетки позволило выявить, что до термообработки в волокне присутствовали „рыхлые“ разориентированные микрообласти, их доля в материале составляла $10-15 \%$.

Термообработка при высоких температурах способствует „залечиванию“ таких дефектов структуры на надмолекулярном уровне, улучшается ориентация цепей, что в итоге приводит к повышению прочности материала $[6,25]$. Если в исходном волокне образования ЖК-типа по данным сорбционных измерений составляют всего

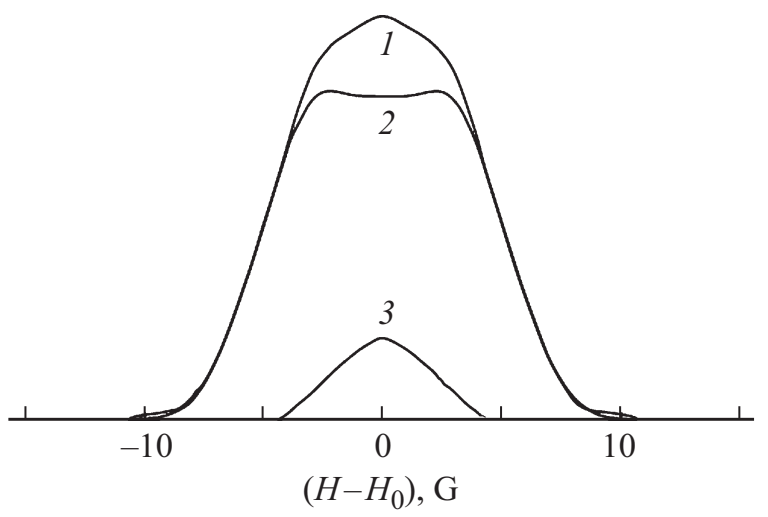

Рис. 5. ПМР-спектры волокон Армос при $-160^{\circ}$ С. 1 - исходное волокно, 2 - термообработанное волокно, 3 - разность спектров 1 и 2. Волокна ориентированы параллельно магнитному полю. 


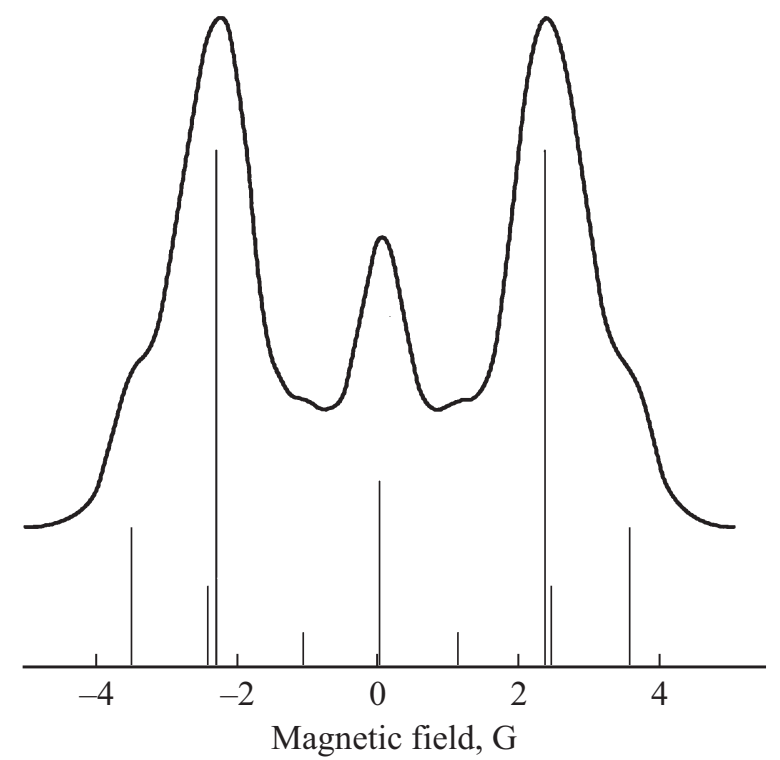

Рис. 6. ПМР-спектр поглощения исходных волокон Vectra A950 при $280^{\circ} \mathrm{C}$. Вертикальные линии - рассчитанные компоненты спектра. Волокна ориентированы параллельно магнитному полю.

лишь 6-7\%, то после термообработки их доля резко возрастает до $\sim 80 \%$, а фактор ориентации фрагментов макромолекул в ЖК-фазе на основании анализа спектров ПМР достигает 0.93 [25].

Такие перестроения в жесткоцепных полимерах становятся возможными благодаря специфическому квазисегментальному движению фрагментов цепей в мезофазе, как первоначально показали исследования на ЖК-сополифире Vectra и ряде других термотропных полимеров [3-6]. На рис. 6 приведен ПМР спектры волокон Vectra, зарегистрированный при температуре $280^{\circ} \mathrm{C}$, когда полимер находится в ЖК-состоянии.

При переходе полимера в ЖК-состояние его ПМРспектр, оставаясь широким, как у твердого тела, распался на ряд компонент, симметрично расположенных относительно центра, свидетельствуя о переходе системы в мезофазу. При этом ЖК-расплав приобретает возможность спонтанной самоорганизации за счет перемещения фрагментов жестких ЖК-цепей относительно друг друга. Квазисегментальная подвижность (в отличие от сегментального движения гибких цепей) осуществляется в условиях высокой степени распрямленности и взаимоориентированности макромолекул в расплаве. Анализ формы ПМР-спектров позволяет количественно оценивать конформационное (змееподобное) движение макромолекул. Оказалось, что такое квазисегментальное движение очень ограничено в пространстве - цепь не выходит за пределы виртуальной трубки диаметром $\sim 2 \mathrm{~nm}$, степень распрямленности движущихся в ориентированном расплаве цепей остается высокой - до 0.9 . Рептации фрагментов в трубке осуществляются в результате случайного накопления смещений, возникающих при локальных колебаниях звеньев цепи по механизму типа Бреслера-Френкеля [26].

Возможность экспериментального исследования локальных форм движения (либрации мезогенов и крутильных колебания вокруг фиксированных связей) по их FIR-спектрам в различных типах жесткоцепных ЖК-полимеров - термотропном (Vectra) и лиотропном (Армос) - показана выше.

В целом особенности молекулярной динамики, выявленные при сравнительном анализе ЖК- и ЖЦ-полимеров по их ИК- и ПМР-спектрам, позволяют яснее представлять картину структурной модификации и динамики мезофаз на молекулярном уровне при тепловых фазовых и релаксационных переходах в подобных системах.

\section{4. Заключение}

Согласно современным теоретическим представлениям о динамике и особенностях релаксационных свойств ЖК- и ЖЦ-полимеров основным механизмом, осуществляющим их термодинамическую гибкость, является не поворотная изомерия, а локальная крутильно-колебательная подвижность цепей. В настоящей работе прямыми методами ПМР и низкочастотной ИК-спектроскопии экспериментально подтверждено существование колебательного механизма равновесной гибкости, обеспечивающего изменение ориентационного состояния и структуры при вытяжке и термообработке жесткоцепных полимеров типа Вектра А950 и Армос за счет случайного накопления валентно-деформационных и крутильно-колебательных смещений при локальных колебаниях в макромолекулах.

\section{Список литературы}

[1] А.В. Волохина, Г.И. Кудрявцев. В сб.: Жидкокристаллические полимеры / Под ред. Н.А. Платэ. Химия, М. (1988). C. $372-415$.

[2] A.A. Levchenko, E.V. Antipov, N.A. Plate. Macromol. Symp. 146, 145 (1999).

[3] E.A. Egorov, V.V. Zhizhenkov. Polymer. 40 3, 3891 (1999).

[4] Е.А. Егоров, В.В. Жиженков. Высокомолекудяр. соединения 44 А, 1119 (2002).

[5] Е.А. Егоров, В.В. Жиженков. Высокомолекуляр. соединения 46 B, 1965.(2004).

[6] Е.А. Егоров, В.В. Жиженков. ФТТ 47 5, 914 (2005).

[7] V.A. Bershtein, V.A. Ryzhov. Adv. Polym. Sci. 114, 43 (1994).

[8] П.деЖен. Физика жидких кисталлов. Мир, М. (1977). $400 \mathrm{c}$.

[9] G. Wiberg, H. Hillborg, U.W. Gedde. Polym. Eng. Sci. 38, 1278 (1998).

[10] А.В. Савицкий, А.Ю. Билибин, И.А. Горшкова. Высокомолекуляр. соединения 34, 143 (1992).

[11] E.A. Egorov, V.V. Zhizhenkov. J. Polym. Sci. Polym. Phys. Ed. 20 7, 1081 (1982).

[12] Tai-Shung Chung, Xin Jin. Polym. Eng. Sci. 40, 841 (2000). 
[13] M. Evans, M. Davies, J. Larkin. Chem. Soc., Faraday Trans. II. 69, 1011 (1973).

[14] M. Takahashi, Y. Kawazoe, Y. Ishikawa, H. Ito. Chem. Phys. Lett. 479, 211 (2009).

[15] S. Ponseca, E. Estacio, H. Murakami, N. Sarukura, R. Pobre, K. Tominaga, J. Nishizawa. J. Phys.: Conf. Ser. 112, 042073C (2008).

[16] P. Simova, N. Kirov. Spectr. Lett. 7, 55 (1974).

[17] I.A. Abbronin, V.A. Rakitina, V.A. Gribanov, M.V. Shablygin. Fibre Chem. 34 2, 140 (2002).

[18] S.M. Shebanov, I.K. Novikov, A.V. Pavlikov, O.B. Anan'in, I.A. Gerasimov. Fibre Chem. 48 2, 158 (2016).

[19] M.V. Shablygin, I.V. Slugin, T.S. Mamonova, L.A. Novikova. Fibre Chem. 41 4, 254 (2009).

[20] S.P. Bagaqutdinova, T.S. Vavilina, S.V. Komissarov, S.G. Sklyarova, M.V. Shablygin. Fibre Chem. 43 2, 174 (2011).

[21] S. Sudha, M. Karabacak, M. Kurt, M. Cinar, N. Sundaraganesan. Spectrochem. Acta 84 A, 184 (2011).

[22] Y. Shyma Mary, P.J. Jojo, C. Yohannan Panicker, Christian Van Alsenoy, Sanaz Ataei, Ilkay Yildiz. Spectrochem. Acta 122 A, 499 (2014).

[23] P.T.T. Wong, A. Garton, D.J. Carlsson, D.M. Wiles. J. Macromol. Sci. Part Phys. 18, 313 (1980).

[24] В.В. Жиженков, Е.А. Егоров, Н.Г. Квачадзе. Физико-химия полимеров 17, 3 (2011).

[25] В.В. Жиженков, С.Ф. Гребенников, К.Н. Бусыгин, Н.Г. Квачадзе, Т.В. Смотрина, В.А. Смотрин. Высокомолекуляр. соединения А 59, 156 (2017).

[26] С.Е. Бреслер, Я.И. Френкель. ЖЭТФ 8, 1094 (1939).

Редактор Ю.Э. Китаев 